\title{
ANALISIS KEBUTUHAN TENAGA KERJA PADA DIVISI OPERASIONAL DI PT. ASIALINK HOLIDAYS SANUR, BALI
}

\author{
Mardi Ulises Simanjuntak \\ I Made Kusuma Negara \\ Email : mardiulises@gmail.com \\ PS. S1 Industri Perjalanan Wisata \\ Fakultas Pariwisata UNUD
}

\begin{abstract}
ABSTRAK
Sehubungan dengan penurunan jumlah wisatawan yang menggunakan jasa PT. Asialink Holidays Sanur, Bali maka berakibat pada Pemutusan Hubungan Kerja (PHK) pada beberapa karyawan. Hal ini menyebabkan kelebihan beban kerja pada karyawan di perusahaan tersebut. Penelitian ini dilakukan dengan tujuan menganalisis lebih lanjut mengenai beban kerja dan kebutuhan tenaga kerja pada PT. Asialink Holidays Sanur, Bali sesuai dengan kondisi yang terjadi pada perusahaan tersebut, khususnya pada divisi operasional.

Jenis data yang digunakan adalah data kualitatif dan data kuantitatif, yang diperoleh dari sumber data, baik primer maupun sekunder. Dalam pengumpulan data dilakukan dengan cara observasi partisipasi, wawancara, dan studi dokumentasi. Penentuan informan dilakukan dengan teknik purposive sampling, yaitu dengan menentukan informan pangkal dan informan kunci. Sementara untuk teknik penentuan sampel adalah berupa penentuan populasi, yaitu seluruh karyawan divisi operasional. Teknik analisis data dalam penelitian ini menggunakan analisis deskriptif kualitatif dan kuantitatif, yang terdiri dari analisis beban kerja, analisis kebutuhan tenaga kerja, tingkat absensi tenaga kerja dan perputaran tenaga kerja.

Dijelaskan bahwa hasil rata-rata pengamatan beban kerja sesuai dengan SOP menunjukkan bahwa karyawan divisi operasional PT. Asialink Holidays Sanur, Bali mengalami kekurangan waktu sebanyak 424 menit, sedangkan yang di luar SOP mengalami kekurangan waktu sebanyak 489 menit. Dengan analisis beban kerja, maka jumlah tenaga kerja divisi operasional yang seharusnya dibutuhkan adalah sebanyak 6 orang.Sementara persentase absensi karyawan divisi operasional pada PT. Asialink Holidays Sanur, Bali tahun 2014 adalah $0,72 \%$ per bulan dan persentase perputaran tenaga kerja pada PT. Asialink Holidays Sanur, Bali tahun 2014 adalah 0, karena tidak ada perputaran tenaga kerja yang terjadi pada tahun tersebut. Maka tenaga kerja yang senyatanya dibutuhkan oleh divisi operasional pada PT. Asialink Holidays Sanur, Bali adalah sebanyak 6 orang. Jumlah karyawan saat ini adalah 2 orang, sehingga PT. Asialink Holidays Sanur, Bali, membutuhkan tambahan tenaga kerja sebanyak 4 orang.

Saran yang dapat diberikan, sebaiknya PT. Asialink Holidays Sanur, Bali segera melakukan perekrutan karyawan agar dapat memenuhi kekurangan tenaga kerja dalam perusahaan. Dengan terpenuhinya kekurangan tenaga kerja, maka beban kerja pun dapat dilaksanakan secara optimal.
\end{abstract}

\section{Kata Kunci : Analisis Kebutuhan Tenaga Kerja, Operasional, Biro Perjalanan Wisata.}

\section{LATAR BELAKANG}

Sebagai salah satu sektor pembangunan yang dapat memacu pertumbuhan ekonomi suatu wilayah, pariwisata dianggap sebagai suatu aset yang strategis untuk mendorong pembangunan pada wilayah-wilayah tertentu yang mempunyai potensi obyek wisata (Sakti, 2014). Dengan adanya pariwisata yang selalu dibangun dan dikembangkan, maka pembangunan industri pariwisata pun turut bersaing demi mendukung kegiatan pariwisata. Industri pariwisata merupakan kumpulan usaha pariwisata yang saling terkait dalam rangka menghasilkan barang atau jasa bagi pemenuhan kebutuhan wisatawan dalam penyelenggaraan pariwisata. Berdasarkan pernyataan tersebut, jelas dikatakan bahwa usaha-usaha yang berhubungan dengan kepariwisataan merupakan usaha yang bersifat komersial.

Salah satu perusahaan yang termasuk industri pariwisata yaitu travel agent atau biro perjalanan wisata. Penyedia jasa layanan ini 
merupakan badan usaha yang memberikan informasi tentang segala sesuatu yang berhubungan dengan dunia perjalanan wisata. Dalam menjalankan tugasnya tersebut, tentu tidak dapat lepas dari adanya sumber daya manusia yang berkualitas, dengan adanya pelatihan atau latar belakang pendidikan yang sesuai. Oleh karena itu perusahaan harus menemukan, mempekerjakan, memotivasi, melatih, dan mengembangkan tenaga kerja yang dikehendaki perusahaan, serta mempertahankan tenaga kerja yang berkualitas. Berikut adalah Tabel jumlah tenaga kerja yang terserap pada industri pariwisata di Provinsi Bali dalam kurun waktu lima tahun :

Tabel 1

Jumlah Tenaga Kerja yang Terserap pada Industri Pariwisata di Provinsi Bali Periode 2011-2015

\begin{tabular}{|c|c|c|c|c|c|c|}
\hline \multirow[b]{2}{*}{ No } & \multirow[b]{2}{*}{ Jenis Usaha } & \multicolumn{5}{|c|}{ Tahun } \\
\hline & & 2011 & 2012 & 2013 & 2014 & 2015 \\
\hline \multirow{4}{*}{1} & \multicolumn{6}{|l|}{ Akomodasi } \\
\hline & $\begin{array}{l}\text { Hotel } \\
\text { Berbintang }\end{array}$ & 29.817 & 29.966 & 29.967 & 30.052 & 30.297 \\
\hline & $\begin{array}{l}\text { Hotel non- } \\
\text { Bintang }\end{array}$ & 18.413 & 18.486 & 18.560 & 18.768 & 18.890 \\
\hline & $\begin{array}{l}\text { Pondok } \\
\text { Wisata }\end{array}$ & 1.980 & 1.988 & 1.998 & 2.102 & 2.241 \\
\hline 2 & $\begin{array}{l}\text { Jasa Boga/ } \\
\text { Restaurant }\end{array}$ & 24.945 & 25.069 & 25.170 & 25.387 & 25.417 \\
\hline 3 & $\begin{array}{l}\text { Jasa } \\
\text { Angkutan \& } \\
\text { Transportasi }\end{array}$ & 4.213 & 4.420 & 4.644 & 4.856 & 4.993 \\
\hline 4 & $\begin{array}{l}\text { Biro } \\
\text { Perjalanan }\end{array}$ & 9.414 & 9.461 & 10.075 & 10.113 & 10.212 \\
\hline \multirow{2}{*}{\multicolumn{2}{|c|}{ Total Pertumbuhan }} & 88.782 & 89.390 & 90.414 & 91.278 & 92.050 \\
\hline & & & $0,68 \%$ & $0,14 \%$ & $0,95 \%$ & $0,84 \%$ \\
\hline
\end{tabular}

Sumber : Dinas Tenaga Kerja Provinsi Bali, 2015

Berdasarkan Tabel 1 di atas dapat diketahui bahwa pada setiap tahunnya jumlah tenaga kerja yang terserap pada industri pariwisata di Provinsi Bali mengalami peningkatan. Hal ini menunjukkan bahwa masyarakat cukup tinggi untuk berpartisipasi dalam upaya pengembangan industri pariwisata di Provinsi Bali.

Industri pariwisata di Bali yang dimaksud adalah PT. Asialink Holidays Sanur, Bali, yaitu penyedia layanan jasa akomodasi, transportasi dan paket wisata. PT. Asialink Holidays Sanur, Bali menjalin kerja sama dengan beberapa travel agent di Belanda. Namun, pada tahun 2014 yang lalu, salah satu dari travel agent besar yang bekerjasama dengan PT. Asialink Holidays Sanur, Bali mengalami collapse hingga akhirnya bangkrut. Hal ini sangat berdampak pada PT. Asialink Holidays Sanur, Bali, mengingat kerja sama yang dilakukan antara kedua pihak tersebut menyangkut jumlah wisatawan mancanegara (Eropa) yang akan melakukan perjalanan wisata ke Bali. Sehingga dengan kondisi tersebut, maka jumlah wisatawan mancanegara khususnya Eropa yang seharusnya menggunakan jasa PT. Asialink Holidays Sanur, Bali menjadi berkurang, seperti yang dipaparkan pada Tabel 2 :

Tabel 2

Jumlah Wisatawan Mancanegara yang Menggunakan Jasa PT. Asialink Holidays Sanur, Bali Tahun 2010-2015

\begin{tabular}{|c|c|r|}
\hline Tahun & $\begin{array}{c}\text { Jumlah } \\
\text { Wisatawan }\end{array}$ & Pertumbuhan (\%) \\
\hline $\mathbf{2 0 1 0}$ & 11.481 & - \\
\hline $\mathbf{2 0 1 1}$ & 10.673 & $-7,04$ \\
\hline $\mathbf{2 0 1 2}$ & 9.782 & $-8,34$ \\
\hline $\mathbf{2 0 1 3}$ & 8.382 & $-14,31$ \\
\hline $\mathbf{2 0 1 4}$ & 8.015 & $-4,37$ \\
\hline $\mathbf{2 0 1 5}$ & 8.512 & $-6,2$ \\
\hline Rata-Rata Pertumbuhan & $\mathbf{- 8 , 0 5}$ \\
\hline
\end{tabular}

Sumber : PT. Asialink Holidays Sanur, Bali, 2015

Pada Tabel 2 tersebut sangat jelas dipaparkan bahwa jumlah wisatawan mancanegara yang menggunakan jasa PT. Asialink Holidays Sanur, Bali dari tahun ke tahun mengalami penurunan. Hal inipun menjadi kondisi terburuk yang terjadi pada PT. Asialink Holidays Sanur, Bali sehingga perusahaan terpaksa melakukan kebijakan Pemutusan Hubungan Kerja (PHK) kepada beberapa karyawan. Selain itu, hal ini juga mempengaruhi kinerja beberapa karyawan PT. Asialink Holidays Sanur, Bali, sehingga ada beberapa karyawan juga yang mengajukan pengunduran diri dalam masa kerjanya mengingat kondisi perusahaan yang semakin menurun.

Jumlah karyawan pada PT. Asialink Holidays Sanur, Bali saat ini adalah sebanyak 15 orang, yang terbagi atas dua departemen yaitu Finance \& Accounting Departement serta Tour Departement, dimana dalam Tour Department tersebut terdiri atas tiga divisi, yaitu divisi operasional, divisi reservasi, dan divisi produk. Penelitian ini dilakukan dengan tujuan menganalisis lebih lanjut mengenai beban kerja dan kebutuhan tenaga kerja pada PT. Asialink Holidays Sanur, Bali sesuai dengan kondisi yang terjadi pada perusahaan tersebut. Dengan menunjuk pada salah satu departemen yang terdapat di PT. Asialink Holidays Sanur, Bali, yaitu pada Tour Departement yang lebih dikhususkan lagi pada satu divisi yaitu divisi operasional. Hal ini juga dilandasi karena pada 
divisi tersebut mengalami tingkat PHK yang cukup tinggi.

Divisi operasional terdiri dari dua orang karyawan tetap. Hal ini sering kali menimbulkan beberapa kendala dalam kesehariannya. Sementara kondisi perusahaan yang saat ini dapat dikatakan sedang dalam masa pemulihan juga menjadi salah satu faktor penting dalam tahapan analisis beban kerja dan kebutuhan tenaga kerja yang dilakukan pada PT. Asialink Holidays Sanur, Bali. Sehingga dapat diketahui jumlah tenaga kerja yang seharusnya dipekerjakan sesuai dengan beban kerja yang ada pada perusahaan, demi terwujudnya hasil kerja yang efektif dan efisien.

\section{METODE}

Lokasi penelitian ini dilakukan di PT. Asialink Holidays Sanur, Bali. Jenis data yang digunakan adalah data kualitatif dan data kuantitatif, yang diperoleh dari sumber data, baik primer maupun sekunder. Dalam pengumpulan data dilakukan dengan cara observasi partisipasi, wawancara, dan studi dokumentasi. Penentuan informan dilakukan dengan teknik purposive sampling, yaitu dengan menentukan informan pangkal dan informan kunci. Sementara untuk teknik penentuan sampel adalah berupa penentuan populasi, yaitu seluruh karyawan divisi operasional di PT. Asialink Holidays Sanur, Bali yaitu sebanyak 2 orang.

Teknik analisis data menggunakan analisis deskriptif kualitatif dan kuantitatif, yang terdiri dari analisis beban kerja, yang terdiri atas pengamatan beban kerja karyawan divisi operasional sesuai Standar Operasional Prosedur (SOP) dan beban kerja karyawan divisi operasional di luar SOP. Sementara dalam melakukan analisis kebutuhan tenaga kerja, perlu dilakukan juga perhitungan terhadap tingkat absensi tenaga kerja serta perputaran tenaga kerja.

\section{HASIL}

\section{Observasi}

Diawali dengan melakukan pengamatan terhadap beban kerja sesuai SOP dan di luar SOP yang disajikan pada tabel berikut :

Tabel 3

Hasil Rata-Rata Pengamatan Beban Kerja Karyawan Divisi Operasional Sesuai SOP pada PT. Asialink Holidays Sanur, Bali

\begin{tabular}{|c|c|c|c|}
\hline Aktivitas & $\begin{array}{c}\text { Kuantitas } \\
\text { Volume }\end{array}$ & $\begin{array}{l}\text { Kuantitas } \\
\text { yang } \\
\text { Diperlukan } \\
\text { (Menit) }\end{array}$ & $\begin{array}{l}\text { Total Alokasi } \\
\text { Waktu } \\
\text { (Menit) }\end{array}$ \\
\hline \multicolumn{4}{|l|}{ Waktu Lingkaran : } \\
\hline Melakukan absensi & 2 & 1 & 2 \\
\hline $\begin{array}{l}\text { Membuka sistem } \\
\text { (log in Travel-E) }\end{array}$ & 1 & 1 & 1 \\
\hline $\begin{array}{l}\text { Memeriksa } \\
\text { permintaan } \\
\text { pemesanan dari tour } \\
\text { operator yang sudah } \\
\text { disetujui oleh } \\
\text { karyawan reservasi }\end{array}$ & 2 & 30 & 60 \\
\hline $\begin{array}{l}\text { Memeriksa dan } \\
\text { membalas email }\end{array}$ & 30 & 5 & 150 \\
\hline $\begin{array}{l}\text { Memeriksa kegiatan } \\
\text { harian }\end{array}$ & 4 & 30 & 120 \\
\hline $\begin{array}{l}\text { Menandatangani } \\
\text { voucher dan } \\
\text { memeriksa semua } \\
\text { pesanan (melakukan } \\
\text { konfirmasi) untuk } \\
\text { hotel, restoran, dan } \\
\text { supplier yang lain }\end{array}$ & 6 & 30 & 180 \\
\hline $\begin{array}{l}\text { Membuat laporan } \\
\text { mingguan kepada } \\
\text { General Manager }\end{array}$ & 1 & 30 & 30 \\
\hline $\begin{array}{l}\text { Memasukkan data } \\
\text { penilaian (kuesioner) } \\
\text { dari wisatawan } \\
\text { terhadap pemandu } \\
\text { wisata }\end{array}$ & 1 & 120 & 120 \\
\hline $\begin{array}{l}\text { Mencetak jadwal } \\
\text { perjalanan paket } \\
\text { wisata }\end{array}$ & 1 & 5 & 5 \\
\hline $\begin{array}{l}\text { Menerima telepon } \\
\text { yang masuk }\end{array}$ & 40 & 3 & 120 \\
\hline $\begin{array}{l}\text { Membuat jadwal } \\
\text { untuk mengunjungi } \\
\text { hotel, restoran, atau } \\
\text { supplier lainnya } \\
\text { untuk memastikan } \\
\text { kontrak kerja yang } \\
\text { masih berlaku }\end{array}$ & 1 & 60 & 60 \\
\hline $\begin{array}{l}\text { Menutup sistem (log } \\
\text { out Travel-E) }\end{array}$ & 1 & 1 & 1 \\
\hline \multicolumn{4}{|c|}{ Waktu Bukan Lingkaran : } \\
\hline $\begin{array}{l}\text { Mempersiapkan } \\
\text { perlengkapan kerja }\end{array}$ & 2 & 5 & 10 \\
\hline $\begin{array}{l}\text { Menghidupkan } \\
\text { computer }\end{array}$ & 1 & 5 & 5 \\
\hline \multicolumn{4}{|l|}{ Waktu Kelelahan : } \\
\hline $\begin{array}{l}\text { Menghilangkan rasa } \\
\text { dahaga }\end{array}$ & 3 & 5 & 15 \\
\hline \multicolumn{4}{|l|}{ Waktu Pribadi : } \\
\hline Pergi ke toilet & 5 & 5 & 25 \\
\hline \multicolumn{3}{|c|}{ Total Waktu yang Dibutuhkan } & 904 \\
\hline \multirow{2}{*}{\multicolumn{3}{|c|}{$\begin{array}{l}\text { Istirahat } \\
\text { Total Keseluruha }\end{array}$}} & 60 \\
\hline & & & 964 \\
\hline
\end{tabular}

Sumber : Hasil Pengamatan, 2015.

Berdasarkan Tabel 3, dapat diperoleh hasil keseluruhan waktu yang diperlukan karyawan divisi operasional untuk menyelesaikan pekerjaan dalam satu hari, yaitu :

$\begin{array}{llr}\text { Waktu Lingkaran } & : & 849 \text { menit } \\ \text { Waktu Bukan Lingkaran } & : & 15 \text { menit } \\ \text { Waktu Kelelahan } & : & 15 \text { menit }\end{array}$ 
Waktu Pribadi

: $\quad 25$ menit

Total

: 904 menit

Berikut pada Tabel 4 diuraikan hasil ratarata dari pengamatan beban kerja karyawan divisi operasional pada PT. Asialink Holidays Sanur, Bali di luar Standar Operasional Prosedur (SOP) atau berdasarkan dengan kondisi yang dialami sehari-hari :

Tabel 4

Hasil Rata-Rata Pengamatan Beban Kerja Karyawan Divisi Operasional di Luar SOP pada PT. Asialink Holidays Sanur, Bali

\begin{tabular}{|c|c|c|c|}
\hline Aktivitas & $\begin{array}{l}\text { Kuantitas } \\
\text { Volume }\end{array}$ & $\begin{array}{l}\text { Kuantitas } \\
\text { yang } \\
\text { Diperlukan } \\
\text { (Menit) } \\
\end{array}$ & $\begin{array}{c}\text { Total Alokasi } \\
\text { Waktu } \\
\text { (Menit) }\end{array}$ \\
\hline \multicolumn{4}{|l|}{ Waktu Lingkaran : } \\
\hline Melakukan absensi & 2 & 1 & 2 \\
\hline $\begin{array}{l}\text { Membuka sistem } \\
\text { (log in Travel-E) }\end{array}$ & 1 & 1 & 1 \\
\hline $\begin{array}{l}\text { Memeriksa } \\
\text { permintaan } \\
\text { pemesanan dari tour } \\
\text { operator yang sudah } \\
\text { disetujui oleh } \\
\text { karyawan reservasi }\end{array}$ & 3 & 60 & 180 \\
\hline $\begin{array}{l}\text { Memeriksa dan } \\
\text { membalas email }\end{array}$ & 30 & 7 & 210 \\
\hline $\begin{array}{l}\text { Memeriksa kegiatan } \\
\text { harian }\end{array}$ & 3 & 30 & 90 \\
\hline $\begin{array}{l}\text { Menandatangani } \\
\text { voucher dan } \\
\text { memeriksa semua } \\
\text { pesanan (melakukan } \\
\text { konfirmasi) untuk } \\
\text { hotel, restoran, dan } \\
\text { supplier yang lain } \\
\end{array}$ & 5 & 20 & 100 \\
\hline $\begin{array}{l}\text { Membuat laporan } \\
\text { mingguan kepada } \\
\text { General Manager }\end{array}$ & 1 & 60 & 60 \\
\hline $\begin{array}{l}\text { Memasukkan data } \\
\text { penilaian (kuesioner) } \\
\text { dari wisatawan } \\
\text { terhadap pemandu } \\
\text { wisata }\end{array}$ & 1 & 120 & 120 \\
\hline $\begin{array}{l}\text { Mencetak jadwal } \\
\text { perjalanan paket } \\
\text { wisata }\end{array}$ & 1 & 10 & 10 \\
\hline $\begin{array}{l}\text { Menerima telepon } \\
\text { yang masuk }\end{array}$ & 50 & 2 & 100 \\
\hline $\begin{array}{l}\text { Membuat jadwal } \\
\text { untuk mengunjungi } \\
\text { hotel, restoran, atau } \\
\text { supplier lainnya } \\
\text { untuk memastikan } \\
\text { kontrak kerja yang } \\
\text { masih berlaku }\end{array}$ & 1 & 60 & 60 \\
\hline $\begin{array}{l}\text { Menutup sistem (log } \\
\text { out Travel-E) }\end{array}$ & 1 & 1 & 1 \\
\hline \multicolumn{4}{|c|}{ Waktu Bukan Lingkaran: } \\
\hline $\begin{array}{l}\text { Mempersiapkan } \\
\text { perlengkapan kerja }\end{array}$ & 2 & 5 & 10 \\
\hline $\begin{array}{l}\text { Menghidupkan } \\
\text { computer }\end{array}$ & 1 & 5 & 5 \\
\hline \multicolumn{4}{|l|}{ Waktu Kelelahan : } \\
\hline Menghilangkan rasa & 5 & 1 & 5 \\
\hline
\end{tabular}

\begin{tabular}{|c|c|c|c|}
\hline \multicolumn{4}{|l|}{ dahaga } \\
\hline \multicolumn{4}{|c|}{ Waktu Pribadi : } \\
\hline Pergi ke toilet & 3 & 5 & 15 \\
\hline \multicolumn{3}{|c|}{ Total Waktu yang Dibutuhkan } & 969 \\
\hline \multicolumn{3}{|c|}{ Istirahat } & 60 \\
\hline \multicolumn{3}{|c|}{ Total Keseluruhan } & 1029 \\
\hline
\end{tabular}

Sumber : Hasil Pengamatan, 2015.

Berdasarkan Tabel 4 di atas, dapat diperoleh hasil keseluruhan waktu yang diperlukan karyawan divisi operasional untuk menyelesaikan pekerjaan dalam satu hari, yaitu :

\begin{tabular}{llr} 
Waktu Lingkaran & $:$ & 934 menit \\
Waktu Bukan Lingkaran & $:$ & 15 menit \\
Waktu Kelelahan & $:$ & 5 menit \\
Waktu Pribadi & $:$ & 15 menit \\
\hline Total & $:$ & 969 menit
\end{tabular}

\section{Perhitungan Analisis Beban Kerja}

Periode yang digunakan adalah tahun 2014, yang terdiri atas 365 hari. Sementara setiap karyawan divisi operasional bekerja sebanyak lima hari dalam satu minggu. Sehingga dapat dihitung jumlah hari kerja karyawan yang sebenarnya sebagai berikut :

Jumlah hari

: 365 hari

Hari libur

: 96 hari

Hari libur nasional

: 15 hari

Cuti dalam setahun

: 12 hari

Jumlah hari kerja sebenarnya : 242 hari

Sehingga dapat diuraikan dalam perhitungan sebagai berikut :

1) Menentukan jumlah tenaga kerja sesuai dengan SOP

$$
\begin{aligned}
\text { Total Man Hours } & =2 \times 904 \times 365 \\
& =659.920 \\
\text { Man Hours Per Unit } & =8 \times 60 \times 242 \\
& =116.160
\end{aligned}
$$

Jadi jumlah tenaga kerja yang dibutuhkan pada divisi operasional adalah sebagai berikut :

WLA

$$
\begin{aligned}
& =\frac{\text { Total Man Hours }}{\text { Man Hours per Unit }} \times 1 \text { orang } \\
& =\frac{659.920}{116.160} \\
& =5,68 \approx 6(\text { dibulatkan menjadi } 6)
\end{aligned}
$$

2) Menentukan jumlah tenaga kerja sesuai dengan beban kerja (di luar SOP)

$$
\begin{aligned}
\text { Total Man Hours } & =2 \times 969 \times 365 \\
& =707.370
\end{aligned}
$$




$$
\begin{aligned}
\text { Man Hours Per Unit } \quad & =8 \times 60 \times 242 \\
& =116.160
\end{aligned}
$$

Jadi jumlah tenaga kerja yang dibutuhkan pada divisi operasional adalah sebagai berikut :

WLA

$$
\begin{aligned}
& =\frac{\text { Total Man Hours }}{\text { Man Hours per Unit }} \times 1 \text { orang } \\
& =\frac{703.370}{116.160} \\
& =6,08 \approx 6(\text { dibulatkan menjadi } 6)
\end{aligned}
$$

\section{Perhitungan Analisis Kebutuhan Tenaga Kerja}

Berikut pada Tabel 5 disajikan jumlah kehadiran dan ketidakhadiran karyawan divisi operasional pada PT. Asialink Holidays Sanur, Bali periode Januari-Desember 2014 :

Tabel 5

Jumlah Absensi Karyawan Divisi Operasional PT. Asialink Holidays Sanur, Bali Periode Januari - Desember 2014

\begin{tabular}{|l|r|r|r|r|r|}
\hline \multicolumn{1}{|c|}{ Bulan } & \multicolumn{1}{|c|}{$\begin{array}{c}\text { Hari } \\
\text { Kerja }\end{array}$} & \multicolumn{1}{c|}{$\begin{array}{c}\text { Tenaga } \\
\text { Kerja }\end{array}$} & $\begin{array}{c}\text { Jumlah } \\
\text { Hari } \\
\text { Kerja }\end{array}$ & $\begin{array}{c}\text { Hadir } \\
\text { (Hari) }\end{array}$ & $\begin{array}{c}\text { Tidak } \\
\text { Hadir } \\
\text { (Hari) }\end{array}$ \\
\hline Januari & 22 & 2 & 44 & 42 & 2 \\
\hline Februari & 20 & 2 & 40 & 38 & 2 \\
\hline Maret & 21 & 2 & 42 & 39 & 3 \\
\hline April & 22 & 2 & 44 & 41 & 3 \\
\hline Mei & 22 & 2 & 44 & 38 & 6 \\
\hline Juni & 21 & 2 & 42 & 40 & 2 \\
\hline Juli & 23 & 2 & 46 & 36 & 10 \\
\hline Agustus & 21 & 2 & 42 & 39 & 3 \\
\hline September & 22 & 2 & 44 & 39 & 5 \\
\hline Oktober & 23 & 2 & 46 & 42 & 4 \\
\hline November & 20 & 2 & 40 & 38 & 2 \\
\hline Desember & 23 & 2 & 46 & 43 & 3 \\
\hline TOTAL & $\mathbf{2 6 0}$ & $\mathbf{2}$ & $\mathbf{5 2 0}$ & $\mathbf{4 7 5}$ & $\mathbf{4 5}$ \\
\hline
\end{tabular}

Sumber : PT. Asialink Holidays Sanur, Bali Tahun 2014

Berdasarkan data pada Tabel 4.4 maka dapat dihitung tingkat absensi karyawan pada divisi operasional dengan menggunakan cara sebagai berikut :

$$
\begin{aligned}
\% \text { Absensi } & =\frac{\text { jumlah hari kerja yang hilang }}{\text { hari karyawan bekerja }+ \text { hari karyawan tidak bekerja }} \times 100 \% \\
& =\frac{45}{475+45} \times 100 \% \\
& =\frac{45}{520} \times 100 \% \\
& =8,65 \% \text { per tahun } \\
& =0,72 \% \text { per bulan }
\end{aligned}
$$

Sementara pada tingkat perputaran tenaga kerja divisi operasional pada PT. Asialink Holidays Sanur, Bali dapat dipaparkan pada Tabel 6 berikut :

Tabel 6

Tingkat Perputaran Tenaga Kerja Divisi Operasional PT. Asialink Holidays Sanur, Bali Periode Januari-Desember 2014

\begin{tabular}{|l|c|c|c|}
\hline Bulan & $\begin{array}{c}\text { Tenaga } \\
\text { Kerja }\end{array}$ & Masuk & Keluar \\
\hline Januari & 2 & - & - \\
\hline Februari & 2 & - & - \\
\hline Maret & 2 & - & - \\
\hline April & 2 & - & - \\
\hline Mei & 2 & - & - \\
\hline Juni & 2 & - & - \\
\hline Juli & 2 & - & - \\
\hline Agustus & 2 & - & - \\
\hline September & 2 & - & - \\
\hline Oktober & 2 & - & - \\
\hline November & 2 & - & - \\
\hline Desember & 2 & - & - \\
\hline Total & 24 & - & - \\
\hline
\end{tabular}

Sumber : PT. Asialink Holidays Sanur, Bali, 2015

Sehingga persentase tingkat perputaran tenaga kerja dapat dihitung sebagai berikut :

$$
\begin{aligned}
\% \text { Perputaran Tenaga Kerja } & =\frac{\text { jumlah pergantian karyawan }}{\text { rata-rata karyawan satu periode }} \times 100 \% \\
& =\frac{0}{24 / 12} \times 100 \\
& =0 \%
\end{aligned}
$$

Sesuai dengan perhitungan tersebut, maka jumlah tenaga kerja yang senyatanya dibutuhkan untuk divisi operasional pada PT. Asialink Holidays Sanur Bali, yaitu :

WFA $=$ WLA $+(\%$ Absensi $x$ WLA + $\%$ Perputaran Tenaga Kerja $x$ WLA)

$=6+(0,72 \% \times 6+0 \% \times 6)$

$=6+(0,0432+0)$

$=6,0432 \approx 6$ (dibulatkan menjadi 6$)$

\section{PEMBAHASAN}

\section{Analisis Beban Kerja (Work Load Analysis)}

Sesuai dengan pendapat Winaya (1994) bahwa analisis beban kerja adalah suatu analisis untuk mengetahui tenaga kerja yang seharusnya dibutuhkan untuk menyelesaikan suatu pekerjaan atau produksi dalam periode tertentu. maka hasil pengamatan yang tersaji pada Tabel 3 dapat terlihat bahwa waktu kerja yang sebenarnya diperlukan adalah 904 menit di luar waktu istirahat (60 menit). Sedangkan waktu efektif bekerja yang tersedia dalam satu hari kerja adalah 8 jam atau 480 menit, maka setiap harinya karyawan pada divisi operasional mengalami kekurangan waktu sebanyak 424 menit.

Sementara pada Tabel 4 dapat dilihat bahwa waktu kerja yang sebenarnya diperlukan adalah 969 menit di luar waktu 
istirahat (60 menit). Sementara waktu efektif bekerja yang tersedia dalam satu hari kerja adalah 8 jam atau 480 menit, maka setiap harinya karyawan divisi operasional mengalami kekurangan waktu sebanyak 489 menit.

Dalam pendapatnya, Ardana., dkk. (2001) juga menyatakan bahwa analisis beban kerja adalah penentuan jumlah tenaga yang diperlukan untuk menyelesaikan suatu pekerjaan dalam jangka waktu tertentu atau penentuan jumlah jam kerja orang (man hours) yang dibutuhkan untuk menyelesaikan suatu beban kerja tertentu dalam periode waktu tertentu, berdasarkan pada pengamatan beban kerja sesuai SOP dan di luar SOP.

Sesuai dengan perhitungan analisis beban kerja dan berdasarkan pada Tabel 3 dan Tabel 4, maka jumlah tenaga kerja divisi operasional pada PT. Asialink Holidays Sanur, Bali yang seharusnya dibutuhkan adalah sebanyak 6 orang.

\section{Analisis Kebutuhan Tenaga Kerja (Work Force Analysis)}

Dalam pendapat Ardana, dkk (2001), analisis kebutuhan tenaga kerja adalah menghitung banyaknya tenaga kerja yang dibutuhkan berdasarkan beban kerja produksi, sehingga akan diperoleh jumlah tenaga kerja yang sesuai untuk menyelesaikan beban produksi yang ditetapkan. Adapun analisis tenaga kerja sangat dipengaruhi oleh persentase absensi dan persentase perputaran tenaga kerja.

Sesuai dengan hasil perhitungan di atas, menyatakan bahwa persentase absensi karyawan divisi operasional pada PT. Asialink Holidays Sanur, Bali adalah 8,65\% per tahun atau $0,72 \%$ per bulan. Sementara berdasarkan Tabel 6 di atas tenaga kerja divisi operasional pada PT. Asialink Holidays Sanur, Bali dalam setahun tidak mengalami perputaran tenaga kerja (0), sehingga persentase perputaran tenaga kerjanya $0 \%$.

Dengan mengacu pada analisis beban kerja dan analisis kebutuhan tenaga kerja divisi operasional pada PT. Asialink Holidays Sanur, Bali, maka didapatkan hasil perhitungan bahwa jumlah tenaga kerja yang senyatanya dibutuhkan adalah sebanyak 6 orang. Jumlah tenaga kerja divisi operasional saat ini adalah sebanyak 2 orang, sehingga PT. Asialink Holidays Sanur, Bali membutuhkan tambahan tenaga kerja sebanyak 4 orang untuk dapat menyelesaikan tugas dan tanggung jawab dari perusahaan.

\section{SIMPULAN DAN SARAN \\ Simpulan}

Berdasarkan hasil dan pembahasan tersebut, maka dapat diambil simpulan sebagai berikut :

1) Berdasarkan hasil rata-rata pengamatan beban kerja sesuai dengan SOP menunjukkan bahwa karyawan divisi operasional PT. Asialink Holidays Sanur, Bali mengalami kekurangan waktu sebanyak 424 menit, sedangkan hasil ratarata pengamatan beban kerja karyawan di luar SOP menunjukkan bahwa karyawan divisi operasional PT. Asialink Holidays Sanur, Bali mengalami kekurangan waktu sebanyak 489 menit. Hal tersebut terjadi karena beban kerja yang terlalu banyak, sementara tenaga kerja yang tersedia kurang. Oleh karena itu, sesuai perhitungan dengan analisis beban kerja, maka jumlah tenaga kerja divisi operasional yang seharusnya dibutuhkan pada PT. Asialink Holidays Sanur, Bali adalah sebanyak 6 orang.

2) Sesuai dengan penelitian yang telah dilakukan, menyatakan bahwa persentase 55absensi karyawan divisi operasional pada PT. Asialink Holidays Sanur, Bali tahun 2014 adalah $0,72 \%$ per bulan. Sementara persentase perputaran tenaga kerja pada PT. Asialink Holidays Sanur, Bali tahun 2014 adalah 0, karena tidak ada perputaran tenaga kerja yang terjadi pada tahun tersebut. Dengan mengacu pada kedua hasil perhitungan tersebut dan analisis beban kerja yang juga telah dilakukan, maka tenaga kerja yang senyatanya dibutuhkan oleh divisi operasional pada PT. Asialink Holidays Sanur, Bali adalah sebanyak 6 orang. Jumlah karyawan saat ini adalah 2 orang, sehingga PT. Asialink Holidays Sanur, Bali, khususnya pada divisi operasional, membutuhkan tambahan tenaga kerja sebanyak 4 orang. 


\section{Saran}

Adapun saran terkait kebutuhan tenaga kerja yang dapat diberikan kepada PT. Asialink Holidays Sanur, Bali adalah : Sebaiknya PT. Asialink Holidays Sanur, Bali segera melakukan perekrutan karyawan agar dapat memenuhi kekurangan tenaga kerja dalam perusahaan. Dengan terpenuhinya kekurangan tenaga kerja, maka beban kerja pun dapat dilaksanakan secara optimal. Hal ini juga bertujuan agar PT. Asialink Holidays Sanur, Bali semakin cepat melalui masa pemulihannya dan kembali mencapai target yang diinginkan.

\section{DAFTAR PUSTAKA}

Ardana, dkk. 2001. Manajemen Sumber Daya Manusia. Denpasar : Universitas Udayana.

Sakti, Zipora Rolentina. 2014. "Peran Masyarakat Dalam Pengembangan Daya Tarik Wisata Taman Nusa di Desa Sidan, Kabupaten Gianyar, Bali". Skripsi. Denpasar : Universitas Udayana.

Winaya, Kuna. 1994. Manajemen Sumber Daya Manusia (Lanjutan), Edisi III Denpasar : Universitas Udayana. 